\title{
A IMPORTÂNCIA DA METAMORFOSE NAS TRA- DUÇÕES DE HERBERTO HELDER
}

\section{THE IMPORTANCE OF METAMORPHOSIS IN HEBERTO HELDER TRANSLATIONS}

\author{
Profa. Dra. Izabela Guimarães Guerra LEAL ${ }^{1}$
}

Rafaella Dias FERNANDEZ ${ }^{2}$

\begin{abstract}
RESUMO: Herberto Helder, em seu trabalho poético tradutório, não utiliza o termo tradução, e sim "poemas mudados para português". Esta forma peculiar de definir o trabalho tradutório já aponta para o gesto de traduzir como um ato de criação literária. É importante compreender que a tradução é um tipo de metamorfose, pois, para Herberto Helder, a metamorfose é a lei que preside toda a criação artística e ela irá ressignificar toda a atividade tradutória. A obra está sempre aberta à tradução e à recriação, isso revela a maleabilidade do objeto poético, o que é essencial para a base da metamorfose. Com isto, o objetivo do presente trabalho será refletir acerca da atividade criativa do tradutor e das relações entre a tradução e a metamorfose e como podemos encontrá-las na obra poética de Herberto Helder.
\end{abstract}

PALAVRAS-CHAVE: Criação; Metamorfose; Tradução; Transformação.

\footnotetext{
${ }^{1}$ Professora Doutora do curso de Letras, da Universidade Federal do Pará. FALE-ILC-UFPA, Belém-Pará-Braisl. E-mail para contato: izabelaleal@gmail.com

${ }^{2}$ Graduada em Letras, Licenciatura em Língua Portuguesa pela Universidade Federal do Pará, Mestranda em Estudos Literários pela mesma Universidade, bolsista CAPES. E-mail para contato: rafaelladias fernandez@hotmail.com.
} 
ABSTRACT: Herberto Helder, in his poetic work of translation, does not use this term, but "poems changed into Portuguese". This peculiar way of defining the work of translation has already point to the action of translation as an act of literary creation. It is important to understand that translation is a kind of metamorphosis, because, for Herberto Helder, the metamorphosis is the law which presides over all artistic creation and it will give another meaning to the entire translation activity. The literary work is always open to translation and recreation, it reveals the malleability of the poetic object, which is essential to the foundation of metamorphosis. With this, the aim of this paper is to reflect upon creative work of the translator and the relationship between the translation and metamorphosis and upon how we can find them in the poetic work of Herberto Helder.

KEYWORDS: Creation; Metamorphosis; Translation; Transformation.

A escrita é esse neutro, esse compósito, esse oblíquo para onde foge o nosso sujeito, o preto-e-branco aonde vem perder-se toda a identidade, a começar precisamente pela do corpo que escreve. Roland Barthes(2004)

A questão da identidade é uma discussão corrente no campo literário, por isso a escolha da epígrafe acima, pois, a partir dela, pretendemos iniciar algumas considerações sobre o papel do escritor, principalmente no que concerne à sua morte. Segundo Barthes (2004), a escrita é a destruição de toda a voz: "a voz perde a sua origem, o autor entra na sua própria morte, a escrita começa” (BARTHES, 2004, p.1).

0 ato de escrita envolve a perda da identidade do autor, a linguagem que surge desse processo passa a ter autonomia sobre o que revela. A identidade não remete mais a quem concretizou as palavras, mas àquele que tomou as palavras para si, o texto escrito. 0 autor entra no 
domínio da própria morte e a escrita surge; nesse processo, há uma transformação, a autoria do texto escrito não pertence mais ao autor, e sim ao leitor, o poder da interpretação do texto é deslocado a quem vai revivê-lo, aquele que o lê. Segundo Barthes (2004), o autor, em proveito da escrita, restitui o seu lugar ao leitor. Como propôs Mallarmé (apud FOCAULT, 2000), é a linguagem quem fala, ela é a detentora do saber sobre o texto, e não mais o autor.

0 autor nasce com o texto e morre nele:

0 autor nunca é nada mais para além daquele que escreve, 'tal' como eu não é senão aquele que diz eu: a linguagem conhece um sujeito, não uma pessoa, e esse sujeito, vazio fora da própria enunciação que o define, basta para fazer suportar a linguagem, quer dizer, para a esgotar (BARTHES, 2004, p.3).

Assim, de acordo com Barthes, a linguagem conhece um sujeito, e não uma pessoa, e esse sujeito vive o instante da escrita, não conseguindo sobreviver fora dela, visto que há o apagamento completo do indivíduo; fora do texto, há um vazio infinito.

Segundo Barthes (2004), a voz que emerge do texto não depende de quem escreve, mas de quem lê, o leitor torna-se o lugar da revelação, o lugar do saber, a unidade do texto não está na sua origem, no seu nascimento, mas sim no seu destino, o valor real da vida do texto quem pode dar é quem o lê, quem o vive: "o nascimento do leitor tem de pagar-se com a morte do Autor" (BARTHES, 2004, p.6). Desta forma, podemos perceber que toda identidade deriva de um afastamento de si e de uma aproximação do outro, nada é evidente por si só nem se sustenta de maneira isolada, o texto não sobrevive só do autor, ele necessita do leitor para lhe dar vida, para renová-lo.

Podemos fazer uso dessa ideia para pensarmos a tradução como criação literária, afinal o afastamento de si e a interação com o outro são pontos fundamentais na atividade tradutória. Para que o tradutor adquira o estatuto de criador, é necessário um distanciamento do que 
é considerado próprio - a cultura e a língua às quais ele pertence - e uma aproximação com o estrangeiro, mas também é necessário que o tradutor se afirme como autor do novo texto, admitindo a liberdade e a autonomia que a tradução poética permite.

Desta forma, ele precisa superar a posição de ser apenas um transmissor do conteúdo do texto original e afirmar-se como autor de um novo texto. A tradução é um processo criador, o novo texto possui elementos que o diferenciam do texto original e, por isso, pode dar origem a uma nova obra. A tradução literária, quando encarada dessa forma, permite que o tradutor seja elevado ao nível do criador, abandonando uma posição estanque de inferioridade.

Berman (2002), um importante teórico francês do século XX, definiu a tradução como um símbolo das maravilhosas translações produzidas diariamente entre as culturas. A tradução, antes de ser uma relação entre línguas, é uma relação entre culturas. A relação com o outro é conflituosa, mas é por meio desse estranhamento que se torna possível o amadurecimento da língua nacional. É somente no contato com o outro que percebemos o quanto a língua materna é incompleta e necessita fundamentalmente da língua alheia para o amadurecimento.

Berman afirma que houve uma necessidade interna da própria tradução de se pensar, de se discutir. Até o século XX, quem discutia e pensava questões relacionadas à atividade tradutória eram os teólogos, filósofos, linguistas, críticos. Isso gerou várias consequências, entre elas, o fato de a tradução permanecer como atividade escondida, subterrânea, pois não se tornava teoricamente autônoma; por outro lado, ela foi vista como atividade inferior, visto que os tradutores não discutiam ou compartilhavam experiências em relação a sua prática.

Por isso o século XX revolucionou os estudos tradutórios, houve a necessidade de se discutir o tema e sua função: "A constituição de uma história da tradução é a primeira tarefa de uma teoria moderna da tradução. Toda modernidade institui não um olhar passadista, mas um movimento de retrospecção que é uma compreensão de si" (BERMAN, 2002, p.12). 
0 retorno ao passado é fundamental para a compreensão do presente.

Nesse retorno ao passado, os estudiosos da tradução comentam que na Idade Média a maior parte das pessoas na Europa falava diversas línguas: "Eles [os poetas] escreviam em várias línguas e para um público que era ele próprio poliglota" (BERMAN, 2002, p.13). Assim, não havia como constituir uma identidade por meio da língua materna, visto que uma determinada língua não era necessariamente priorizada em detrimento de outra. Por essa razão, os poetas brincavam constantemente com as variações linguísticas das línguas e as misturavam, sem que isso causasse um prejuízo para a leitura ou uma aversão do público.

Ainda refletindo sobre o que Berman (2002) propõe, podemos perceber que o tradutor, por mais que se esforce, estará sempre em uma posição suspeita, insatisfatória, em um entre-lugar, sempre fadado ao famoso adágio italiano, traduttore traditore. Nos estudos sobre tradução, essa questão do tradutor como traidor sempre é algo importante a ser debatido, afinal, o que está em jogo na tradução? A fidelidade ou a traição? Como já se perguntava Schleiermacher (apud BERMAN, 2002), trata-se de servir à obra, ao autor, à língua estrangeira, ou de servir ao público, à língua materna?Segundo o autor, esse é o drama do tradutor, ele sempre terá que renunciar a uma das línguas, não é possível conciliar os dois senhores. De qualquer forma, o tradutor não conseguirá ser totalmente neutro, algo da relação com o outro sempre estará em aberto, como em toda relação com o estrangeiro.

Berman (2002) afirma que, de certa forma, toda cultura resiste à tradução, mesmo que precise essencialmente dela: "A própria visada da tradução - abrir no nível da escrita uma certa relação com o Outro, fecundar o Próprio pela mediação do Estrangeiro - choca-se de frente com a estrutura etnocêntrica de qualquer cultura (...)" (BERMAN, 2002, p.16). Assim, percebemos que há o choque cultural, pois é como se cada sociedade desejasse ser autossuficiente, ter uma identidade pura, sem contato externo.

Nessa reflexão, Berman argumenta ainda que não importa que no 
nível da realidade não seja possível manter uma língua e uma cultura intacta, sem contato alheio: "Trata-se aqui de desejos inconscientes. Qualquer cultura desejaria ser suficiente em si mesma para, a partir dessa suficiência imaginária, ao mesmo tempo brilhar sobre as outras e apropriar-se de seu patrimônio" (BERMAN, 2002, p.17). Assim, pensando nessa questão etnocêntrica, a tradução ocupa um lugar contraditório.

A tradução, por um lado, se submete a uma injunção apropriadora, o que leva a produzir traduções etnocêntricas, ou o que o autor denomina de "má" tradução, mas, por outro lado, o ato de traduzir opõe-se completamente a essa natureza, visto que a tradução é, por excelência, esse contato com o outro: "a essência da tradução é ser abertura, diálogo, mestiçagem, descentralização. Ela é relação, ou não é nada" (BERMAN, 2002, p.17).

Desta forma, o autor termina suas considerações sobre a tradução concluindo que há três eixos que podem definir e que devem fazer parte de toda reflexão moderna, o primeiro é a história da tradução, o que envolve o percurso de reconstrução da atividade tradutória, o segundo é a ética da tradução, que discute a questão da mestiçagem, do envolvimento com outras culturas, da mistura e do estranhamento presente na relação com o outro, e o último é a analítica da tradução, que envolve a dialética presente nessa tarefa, o impasse que o tradutor encara ao se deparar com as noções de fidelidade e traição.

Nesse último ponto, o autor considera que o tradutor quebra as barreiras presentes nas duas línguas, forçando a sua própria à estranheza alheia e forçando a outra língua a acomodar-se à sua língua materna. Assim, podemos inferir que o tradutor é movido por uma pulsão tradutória, por um ímpeto, um desejo de transformar a língua estrangeira, por um instante, em língua materna, ou de transformar a língua materna em língua estrangeira, de fazer com que ambas, por um momento, se transformem em uma só.

Essa ação do tradutor faz com que a obra traduzida sofra uma rege- 
neração, uma potencialização, além das perdas e dos ganhos essenciais nesta passagem, há algo novo que não está em nenhuma dessas categorias, algo além do social, do cultural, da mestiçagem, algo que está na essência da própria linguagem.

A tarefa do tradutor é trabalhar nesta potencialização, nesta transformação da obra, rompendo as barreiras do próprio.Podemos utilizar, como exemplo, a história citada por Berman (2002) sobre o poeta holandês Hooft, o qual,em virtude da morte da mulher amada, compôs uma série de epitáfios, primeiramente na língua materna, o holandês, depois em latim, em francês, novamente no latim, depois em italiano, e, um pouco mais tarde, novamente no holandês.

Podemos inferir com esta atitude do poeta que a língua materna não foi suficiente para expressar a sua dor. 0 poeta sentiu a necessidade de passear por várias línguas e de realizar auto-traduções para chegar a uma justa expressão da dor em sua língua materna. Todo esse caminho percorrido entre línguas ocorreu por um estranhamento com a própria língua materna, podemos supor que o holandês não foi o bastante para o poeta expressar sua dor e ele sentiu esta necessidade de passar por outras línguas para chegar a uma sensação justa do luto em língua materna. Manter opções do autor aqui.

O passeio por outras línguas e a ação de passar por diversas autotraduções ajudaram o poeta a superar essa dor e podemos inferir que se tivéssemos acesso a essas traduções, possivelmente perceberíamos que a primeira versão e a última em holandês, mesmo sendo do mesmo idioma, são completamente diferentes, nesse processo houve várias perdas, ganhos, transformações.

Este exemplo nos revela que a língua materna não foi suficiente para o poeta, a língua holandesa deveria acolher a sua dor, mas ela era tão grande que foi fundamental passar por esse processo tradutório, por essa violência de trabalhar com o luto em outras línguas, por esse amadurecimento para poder, enfim, regressar da dor e se expressar na língua própria. A tradução abala o bem-estar que achamos possuir em 
língua materna, pois a atividade tradutória revela que a língua própria às vezes não é suficiente como forma de expressão.

Nesse sentindo, o afastamento da língua própria não é visto como algo ruim, mas sim como uma ação essencial e produtiva para geraroutra maneira de habitar a língua materna, como podemos ver nesta citação de Izabela Leal (2011):

A tradução encarna não a afirmação da língua/cultura materna, mas sim a -necessidade de abandoná-la. Cumpre observar que abandonar a língua/cultura própria não significa rechaçá-la, mas sim compreendê-la a partir de um distanciamento necessário. Trata-se de um afastamento produtivo, pois é apenas com a distância que podemos ter a dimensão do próximo (LEAL, 2011a, p.128).

A partir disto, podemos afirmar que o poeta holandês sentiu a necessidade do passeio pelo estrangeiro para poder aceitar o luto na língua própria, a tradução é um processo de estranhamento, e essa estranheza é inerente à experiência de viver entre línguas, entre culturas diferentes; se não houvesse essas diferenças entre línguas, entre culturas, e se o acesso ao outro fosse realizado sem obstáculos, significaria que todos se entendem e compartilham dos mesmos costumes, não haveria discussões, mudanças, amadurecimento por ambas as partes, desta forma, a violência tradutória serve para nos revelar o outro, o diferente: "vivemos entre línguas e é nesse lugar, entre elas, que se infiltra toda a experiência do mundo"(MORAES, 2011, p.49). A partir disto, podemos inferir que foi pela experiência de ter passeado e vivido entre outras línguas que o poeta holandês pode, enfim, expressar-se em sua língua materna.

A tradução literária oferece ao tradutor a liberdade de se consagrar como escritor, como autor do texto traduzido, desta maneira, o tradutor precisa arcar com certas responsabilidades autorais e se desprender do texto na língua estrangeira para concluir sua tarefa de forma livre, e essa liberdade pode ou não estar de acordo com certas intenções comunicativas do autor do texto original. 0 texto de tradução precisa responder 
como texto de autoria, e não como mera cópia do original.

Lages (2007), importante estudiosa contemporânea da tradução, afirma que o panorama atual da tradução possui divergências, pois há uma diversidade de argumentos e posições em relação ao papel do tradutor. As correntes atuais possuem uma complexidade teórica e é necessário fazer uma breve análise para entender a origem do aspecto melancólico que acompanha o tradutor no seu percurso histórico.

A autora afirma que o tradutor possui um papel duplo, pois, por um lado, há um rebaixamento de sua tarefa, uma desvalorização de sua posição em relação ao autor do texto, mas, por outro lado, há uma exacerbação do seu papel, há exigências que praticamente obrigam o tradutor a ter capacidades consideradas sobre-humanas, no que diz respeito a conhecimentos linguísticos:

Nesse sentido, a história da tradução e da imagem do tradutor que escritores, filósofos e os próprios tradutores e teóricos da tradução forjaram ao longo dos séculos pode ser descrita como uma história de rebaixamentos, auto-reproches, enfim, de uma constante desvalorização da pessoa, do ego, do tradutor, por um lado; por outro, há uma exigência - evidentemente exagerada - de capacidades sobre-humanas a serem dominadas pelo tradutor, em termos da abrangência de seus conhecimentos culturais e linguísticos (LAGES, 2007, p.65).

Desta forma, a autora propõe uma discussão sobre o aspecto melancólico que acompanha a tradução desde sempre, e propõe debater o verdadeiro papel do tradutor como autor do novo texto: "O tradutor deve, acima de tudo e necessariamente, ser reconhecido como escritor, autor do texto traduzido, a partir de determinações históricas particulares e específicas a cada caso"(LAGES, 2007, p.75).

A principal corrente exposta por Lages (2007) e a que possui maior relevância para esse trabalho é a que vê a tradução como transcriação. Este conceito nasceu com a poesia concreta, visto que a tradução ocupa um lugar de destaque no projeto concretista, junto com a poesia e a críti- 
ca. Para os fundadores deste movimento, Augusto e Haroldo de Campos e Décio Pignatari (apud LAGES, 2002), o importante é buscar na poesia o que ela tem de mais próprio, de mais singular, de essencial, assim como na tradução, já que o tradutor deve buscar no estrangeiro aquilo que tem de único, o diferencial.

0 conceito de antropofagia é resgatado da semana de arte moderna de 1922 e readaptado para o ideal concretista, passando a ser o elemento essencial do movimento por representar uma leitura específica da tradição: "Trata-se de um processo de violenta apropriação, que se constitui a partir de uma leitura conscientemente seletiva do substrato literário passado e contemporâneo" (LAGES, 2007, p.90).

A apropriação é feita da energia vital do outro, por isso é um processo violento, há uma destruição do estrangeiro, a barreira do nacional é quebrada nesse processo, o outro é utilizado e filtrado, há uma escolha do que se quer apropriar. 0 mesmo ocorre com a tradução e nesse sentido podemos dizer que também há uma traição neste processo, pois o tradutor funciona como um invasor, e não leva para sua língua tudo que encontra no estrangeiro, apenas aquilo que lhe interessa.

Assim, a tradução é uma forma de intertextualidade, é uma apropriação do que a cultura do outro tem de melhor. Perrone-Moisés (1990), utiliza o termo antropofagia cultural, também emprestado de Oswald de Andrade, para nomear esse rapto da cultura alheia. 0 termo foi proposto com o intuito de nomear a devoração crítica no Modernismo. A metáfora da Antropofagia é baseada na cultura indígena. Para os índios, devorar o outro representava adquirir suas virtudes e qualidades.

Há, na devoração, uma escolha, assim como no processo de intertextualidade. No caso da tradução, essa seleção é bem visível na escolha do tradutor em relação à obra a ser traduzida. Rónai (1956), crítico e tradutor, acredita que há razões para a escolha da obra a ser utilizada na tradução. Há um encontro entre o tradutor e a obra original, há uma ligação entre as línguas, há um brilho com a união de ambas.

Para o autor, essas explicações são: a afinidade com o autor, a desco- 
berta de uma grande matéria-prima ou a "sensação de se encontrar em transe parecido ao em que já se debateu o grande estrangeiro, o qual se torna assim um irmão na infelicidade" (RÓNAI, 1956, p.36). A infelicidade talvez seja um ponto em comum entre o tradutor e o autor, por representar exatamente a falha que a língua própria possui, sendo revelada somente na atividade tradutória. Ambas são incompletas, a falha já vem desde a língua materna e da obra original, a infelicidade é um sentimento que perpassa a obra desde o seu nascimento.

Assim, a tradução possibilita um trabalho de criação, na medida em que o tradutor consegue se afastar da língua materna e se aproximar da língua estrangeira e produzir, a partir desta experiência, um texto renovado, original. Rónai (1956) definiu a tradução como arte. Para o autor, o objetivo de toda arte é algo impossível, pois o poeta tenta exprimir o inexprimível, o pintor tenta reproduzir o irreproduzível e o tradutor se empenha em traduzir o intraduzível.

Este breve percurso feito sobre a história da tradução é fundamental para introduzirmos uma visão muito peculiar sobre o tema, que é a visão do poeta português contemporâneo Herberto Helder. Em suas obras, o poeta não denomina seus textos de tradução, o termo empregado por ele é "poemas mudados para português". Esta forma de nomear o trabalho tradutório aponta para o gesto de traduzir como criação literária, como criação poética.

Segundo Maria Etelvina Santos (1998), ensaísta portuguesa e estudiosa da obra herbertiana: "o interesse de Herberto Helder pela tradução, no sentido mais amplo de recriação das palavras de outros, surge, desde sempre, interligado com a sua escrita poética própria" (SANTOS, 1998, p.5).

Herberto Helder compreende a tradução como um tipo de metamorfose. Para ele, é por meio da metamorfose que se torna possível uma transfiguração do real em algo superior, ressignificando o sentido dos seres e das coisas. A tradução força os limites e barreiras entre as línguas, da mesma forma que a metamorfose força as barreiras e dissolve 
os limites dos corpos. A compreensão do sentido da metamorfose é fundamental para introduzir a poética herbertiana e o seu modo de entender a tradução.

Para Herberto Helder, no processo de tradução há uma violência entre as línguas, a atividade tradutória não se afasta de um processo de ruptura, de desagregação: “A prática tradutória, para Herberto Helder, é uma prática deformadora e violadora da língua materna; apenas no impasse de traduzir é que nos damos conta das falhas da nossa língua" (LEAL, 2011b, p.32). Assim, como veremos a seguir, é pela tradução que podemos perceber as falhas existentes na nossa língua e a importância da troca de fluxos com o estrangeiro para um amadurecimento e uma renovação cultural.

A base sobre a qual é construída a poética de Herberto Helder é a ideia constante de transformação. Para o poeta, o poema é algo que está em constante movimento, obedecendo apenas a uma lei: a da metamorfose,como o próprio autor nos mostra no conhecidíssimo texto de Retrato em Movimento (1968), que, mais tarde, seria integrado e transformado em um conto de Os Passos em Volta (1997), sob o título de Teoria das Cores.

A partir deste conto, é possível fazer algumas considerações acerca da poética de Herberto Helder. Para o autor, a lei da metamorfose é a lei que preside toda criação artística, pois o pintor estava pintando o peixe que ele acreditava ser vermelho e, no processo de passar o que estava vendo para o quadro, o peixe mudou de cor. Desta forma, a mudança aconteceu no momento em que o pintor ia concretizar uma imagem fixa do peixe em um quadro, o que, na verdade, não existe, já que a realidade está em constante modificação. Ao pensar que o peixe era uma estrutura fixa, o próprio peixe mostrou ser instável, ser flexível a outras condições.

A ideia de transformação remete ao deslocamento. Na poesia herbertiana os seres e as coisas estão sofrendo constantes alterações, são mecanismos totalmente flexíveis e instáveis. A atividade de mutação é retratada no conto, sendo o peixe o corpo material que torna possível a desarticulação daquilo que é imóvel, mostrando, assim, a flexibilidade 
da matéria, não sendo possível reduzir nada a um sentindo único, definitivo.

O mesmo acontece com o poema, que está em constante movimento. Herberto Helder afirmou que o livro flutua e que está em constante suspensão. Assim também é o poema, está sempre se modificando, aceitando variadas possibilidades de leitura. Então, o objetivo do poeta é trabalhar na transformação, na metamorfose, como fez o pintor, que entendeu o que acontecera e abriu mão da realidade, permitindo a liberdade artística.

O conto também aborda a questão da fidelidade, pois o poeta acreditava estar sendo fiel à imagem que estava vendo do peixe e, ao tentar concretizá-la, percebeu que a fidelidade não existe. Assim, para Herberto Helder, o artista só deve ser fiel à lei da metamorfose. É com base nesta lei que preside todo o trabalho artístico e poético que pensaremos o trabalho tradutório realizado por Herberto Helder.

0 conto em questão pode servir como modelo para avaliarmos o trabalho de tradução realizado pelo poeta. A tradução, no sentido que daremos a ela, será aquela em que o tradutor, assim como o pintor no conto Teoria das Cores, não busca a fidelidade em relação à obra original. 0 importante é a possibilidade de modificar a própria língua materna e de recuperar o brilho do original na obra traduzida.

Santos (1998) afirma: "a poesia de Herberto Helder se orienta por um fazer poético que sempre é o da deambulação, da revisitação da própria obra, no sentido de uma busca constante cujo objectivo consiste em dar a ver o que existe de mais profundo e elementar em cada homem" (SANTOS, 1998, p.1). Assim, temos como exemplo desse trabalho de revisitação da própria obra o conto Teoria das cores, no qual o próprio poeta se revela instável às transformações do mundo, praticando a auto -intertextualidade.

Ainda refletindo sobre a tradução, Walter Benjamin, em seu célebre ensaio intitulado A tarefa do tradutor (2008), afirma que todos os gestos realizados na tradução são feitos por algum tipo de amor à língua. Para Ben- 
jamin, a tradução, ao invés de querer se assemelhar ao sentido do original, deve antes se configurar como um gesto de amor, levando em consideração os pormenores do modo de querer dizer do original, para que ambos, original e tradução, possam ser reconhecíveis em uma língua maior.

A metáfora utilizada por Benjamin (2008) é a dos cacos de um vaso. Se os fragmentos do vaso forem unidos, eles vão apontar para o que seria um vaso, mas não vão conseguir representar o vaso em si. Assim, o original e a tradução devem apontar para uma língua maior, superior, tal como os cacos representam fragmentos do vaso inteiro.

Para Benjamin, a boa tradução não visa servir ao leitor, pelo contrário, a forma como vai ser recebida não importa, o importante é tentar buscar uma relação íntima e profunda entre as obras e entre as línguas. A tradução deve ser transparente, ela não deve ocultar o brilho do original, e sim fazer com que haja um duplo brilho, com a mistura de ambas as línguas.

Lembremos que Benjamin, nesse ensaio, utilizou a palavra Aufgabe do alemão que possui duplo significado, o de tarefa-renúncia, assim, o tradutor vive um impasse ao traduzir, ele possui a tarefa de renovação, tanto da obra quanto da própria língua materna, mas, simultaneamente, precisa renunciar ao exercício de traduzir exatamente o que estava na língua original.

A tradução possibilita a Herberto Helder o trabalho de citação e de apropriação de outros poetas, visto que nem sempre o poeta especifica quem está citando: "Se Herberto Helder cita outros poetas é porque considera que há uma forma produtiva de citação, e que me parece ser a utilizada por aqueles que, como ele, são capazes de entrar no tempo mítico do poema" (SANTOS, 1998, p.4). Assim, percebemos que a apropriação do estrangeiro é algo positivo na poética herbertiana, pois o poeta consegue transmutar o que está na obra alheia e implantá-lo na sua obra. Há uma relação muito próxima entre o trabalho de citação e o trabalho de transmutação, e as obras de Herberto Helder são um exemplo disso, como o próprio poeta define em um de seus livros: 
A transmutação é o fundamento geral e universal do mundo. Alcança as coisas, os animais e o homem como o seu corpo e a sua linguagem. Trabalhar na transmutação, na transformação, na metamorfose, é obra própria nossa. (...) o poema é o corpo da transmutação, a árvore do ouro, vida transformada: a obra (HELDER, 1977, p. 21).

Novamente podemos ver que o trabalho de tradução não se afasta do próprio trabalho de criação, ambos estão relacionados a um processo de transformação da língua. Ambos buscam uma mudança para a língua, uma forma de metamorfosear seus sentidos denotativos e ressignificá -los. Em suas obras poéticas, Herberto Helder procura essa deformação, essa transformação da língua, levando em consideração todas as possibilidades que a liberdade tradutória oferece. 0 poema abaixo,uma tradução realizada por Herberto Helder do poeta polonês Zbigniew Herbert, é um exemplo de seu trabalho poético tradutório,pois nele podemos perceber várias das implicações sobre a própria visão do poeta português em relação à atividade tradutória:

- Sobre tradução de poesia -

Zumbindo um besouro pousa

numa flor e encurva

o caule delgado

e anda por entre filas de pétalas folhas

de dicionários

e vai direto ao centro

do aroma e da doçura

e embora transtornado perca

o sentido do gosto

continua

até bater com a cabeça

no pistilo amarelo

e agora o difícil o mais extremo

penetrar floralmente através

dos cálices até

a raiz e depois bêbado e glorioso

zumbir forte: 
penetrei dentro dentro dentro

e mostrar aos cépticos a cabeça

coberta de ouro

de pólen

A partir deste poema, podemos fazer algumas considerações sobre a tarefa de traduzir poesia. Podemos associar o besouro ao tradutor, e a primeira ação presente no poema é o encontro entre o tradutor e a obra a ser traduzida: "Zumbindo um besouro pousa/numa flor e encurva/o caule delgado." 0 tradutor encontrou sua obra, teve o primeiro contato e agora pensa em como vai prosseguir: "e anda por entre filas de pétalas folhas/de dicionários".

Após esse contato com a obra, o tradutor encontra a essência do poema, encontra o elemento peculiar presente na outra língua: "e vai direto ao centro/do aroma e da doçura", e sofre o estranhamento com esse contato, sofre a violência de estar em território alheio e de ultrapassar as barreiras do próprio: "e embora transtornado perca/o sentido do gosto/ continua/até bater com a cabeça/no pistilo amarelo",mas o tradutor supera essa barreira e ultrapassa os limites da língua.

Depois desse estranhamento, ainda resta transpor para a língua materna toda essa emoção vivida em território estrangeiro: "e agora o difícil o mais extremo/penetrar floralmente através/dos cálices até/a raiz e depois bêbado e glorioso/zumbir forte/penetrei dentro dentro dentro/e mostrar aos cépticos a cabeça/coberta de ouro/de pólen”.

O importante é destacar que a cabeça do besouro ressurgiu coberta de ouro; ainda inferindo que o besouro corresponde ao tradutor, podemos afirmar que o tradutor conseguiu transpor o que há de mais importante, de mais precioso, visto que o ouro é o metal mais puro, o metal verdadeiro por excelência, assim sendo, o tradutor conseguiu realizar sua tarefa ao transpor para a língua materna o que encontrou de fundamental na língua alheia. De todo modo, há os resquícios do outro no poema, há as marcas do estranhamento, da violência de ultrapassar as línguas e isso não há como retirar da obra, os resquícios do outro esta- 
rão presentes na tradução, pois o outro também deixa suas marcas após o contato, essa mistura entre as línguas faz parte da atividade tradutória. No fim, o tradutor conseguiu superar as barreiras entre as línguas e revelou ao mundo que é possível fazer tradução de poesia, é possível transpor o elemento extraordinário do estrangeiro. E cobrir-se de ouro.

\section{REFERÊNCIAS}

BARTHES, R. A morte do autor. Texto publicado em: 0 rumor da língua. São Paulo: Martins Fontes, 2004.

BENJAMIN, W. A tarefa do tradutor. Quatro traduções para o português. Organização de Lúcia Castelo Branco. Belo Horizonte, Fale/ UFMG, 2008.

BERMAN, A. A prova do estrangeiro: cultura e tradução na Alemanha romântica. Tradução de Maria Emília Pereira Chanut. Bauru, SP: EDUSC, 2002.

CAMPOS, Haroldo de. Poética da tradução. In: A arte no horizonte do provável. São Paulo: Perspectiva, 1975.

FOUCAULT, Michel. As palavras e as coisas- uma arqueologia das ciências humanas. Tradução de Salma Tannus Muchail. Martins Fontes, São Paulo, 2000.

HELDER, H. 0 corpo oluxo aobra. Lisboa: Assírio \& Alvim, 1977.

Os passos em volta. Lisboa: Assírio \& Alvim, 1997.

LAGES, S. K. Walter Benjamin: tradução e melancolia. São Paulo: EDUSP, 2002. 
LEAL, G.G.I. "Serpiente y panuelo": a busca das raízes ameríndias em José Lezama Lima e Herberto Helder. In: ALENCAR, A.; LEAL, G.G.I.; MEIRA, C. (Org.) Tradução literária: a vertigem do próximo. Rio de Janeiro: Beco do Azougue, 2011a, p. 119-129.

.Da memória á tradução: o erro das musas distraídas. In: JACOTO, L.; MAFFEI, L. (Org.) Soldado aos laços das constelações HerbertoHelder. São Paulo: Lumme, 2011b, p.25-35.

MOISES, L. P. Flores da escrivaninha. São Paulo: Companhia das letras, 1990.

MORAES, M. J. Viver entre línguas: língua, lugar/tradução da experiência? In: ALENCAR, A.; LEAL, G.G.I.; MEIRA, C. (Org.) . Tradução literária: a vertigem do próximo. Rio de Janeiro: Beco do Azougue, 2011, p. 39-51.

RONÁI, P. Escola de Tradutores. 5ํe ed. ver. ampl. Rio de Janeiro: Nova Fronteira/INL, 1987.

SANTOS, M. E.. HerbertoHelder - Territórios de uma poética. Revista Semear Rio de Janeiro: Cátedra/PUC, dez/1998. Disponível em <http://www.letras.puc-rio.br/catedra/revista/semiar 4.html>. Acesso em: <12/12/2012>. 